\title{
Atividades de tradução em um livro didático de língua inglesa
}

\author{
ARAÚJO, Angelica Almeida ${ }^{1}$ \\ BRANCO, Sinara de Oliveira ${ }^{2}$
}

Resumo: Este trabalho tem o objetivo de identificar exercícios em um livro didático de língua inglesa que incluam as três categorias de tradução - Intersemiótica, Intralingual e Interlingual. A Fundamentação Teórica é baseada na Abordagem Funcionalista de Tradução e nas Categorias de Tradução anteriormente citadas. Foram selecionadas as atividades que incluíssem uma ou mais categorias de tradução e, em seguida, foi observada a forma de aplicação das atividades e o nível linguístico proposto para aplicação delas. A análise demonstrou que o uso mais recorrente no material investigado é o da categoria de tradução Intersemiótica. Portanto, concluiu-se que, no nível básico de aprendizado de LE, o uso de imagens, fotos, cores e demais elementos não verbais são um auxílio fundamental para o desenvolvimento de uma LE.

PAlAVRAS-CHAVE: Abordagem Funcionalista de Tradução; Categorias de Tradução; Ensino de Línguas Estrangeiras.

\section{INTRODUÇÃO}

O uso do material didático no ensino de uma língua estrangeira é de grande relevância para o desenvolvimento do indivíduo enquanto aluno. Observa-se que o uso de tradução em livros deste tipo tem auxiliado no aprendizado de idiomas. Por tal razão, o objetivo deste trabalho é mapear as atividades que envolvem categorias de tradução em um livro didático utilizado no curso de extensão da Universidade Federal de Campina Grande, com a intenção de analisar qual a aplicação prática do uso da(s) categoria(s) mais recorrente(s) neste material.

A coleta de dados em um livro de inglês da coleção 'English File', que é utilizada nas aulas de extensão da Universidade Federal de Campina Grande, foi iniciada com a intenção de identificar exercícios que pudessem ser trabalhados com auxílio da ferramenta de tradução; envolvendo as três categorias tradutórias expostas por Jakobson (1958, In VENUTI, 2000 - p.114): 1) a “Tradução Intralingual é uma interpretação de signos verbais por outros signos da mesma língua"; 2) a "Tradução

\footnotetext{
${ }^{1}$ Aluna do Curso de Letras-Inglês, Unidade Acadêmica de Letras, UFCG, Campina Grande, PB, E-mail: angelicaaaraujo@gmail.com.

${ }^{2}$ Letras, Professora. Doutora, Unidade Acadêmica de Letras, UFCG, Campina Grande, PB, E-mail: sinarabranco@gmail.com. *Autor para correspondências.
} 
Interlingual é a interpretação de signos verbais por significados verbais de outra língua"; e 3) a "Tradução Intersemiótica é uma interpretação de signos verbais por significados de signos de um sistema de signos não-verbais”. (JAKOBSON, 1958/2000. p. 114).

Após a coleta de dados, foi iniciado o mapeamento de atividades que trabalhassem de alguma forma com a tradução, contabilizando-as e separando-as e entre as três categorias propostas por Jakobson, para que assim pudéssemos observar a ocorrência de determinadas categorias nas atividades, procurando investigar a razão da ocorrência maior de atividades envolvendo a categoria intersemiótica no corpus analisado.

Foi também analisado o uso dessas atividades envolvendo uma visão da tradução relacionada a um modelo mais atual: a Abordagem Funcionalista da Tradução segundo Nord (1997). Este modelo descreve a tradução com propósitos e objetivos direcionados a um trabalho específico, neste caso, à sala de aula de aprendizagem de língua inglesa. A abordagem de Nord será apresentada a seguir.

\section{TEORIA FUNCIONALISTA DE TRADUÇÃO}

A teoria funcionalista de tradução tem foco na atividade de tradução direcionada ao leitor do texto traduzido, levando em consideração este leitor, a função - ou funções do texto traduzido e o contexto em que eles (leitor e texto) estão inseridos. Essa teoria apresenta a ideia de que o texto traduzido será produzido dependendo de um propósito que irá variar de acordo com a cultura da língua-alvo e do público que fará uso de tal texto. Nessa abordagem, o texto original deixa de ter o papel de fonte principal de informação para a produção do texto traduzido, pois a tradução funcionalista prioriza o objetivo da tradução, considerando-a uma recriação, e não apenas uma cópia ou transposição linguística do texto original.

Nord (1997) segue a sugestão de Reiss (1977), que desenvolveu um modelo de crítica tradutória baseada no conceito de equivalência linguística entre duas línguas e na relação entre texto-fonte e texto-alvo. Entretanto, Reiss (1977) tem consciência de que há situações em que a equivalência não é possível, ou sequer desejada. Essas situações são nomeadas pela teórica como exceções, e uma dessas exceções surge quando a intenção do texto traduzido difere do propósito do texto original. É nesse ponto que Nord (op.cit.) desenvolve a Abordagem Funcionalista da Tradução, sugerindo que um texto traduzido não necessariamente terá o mesmo propósito do texto original. 
A visão funcionalista enxerga a atividade de tradução como interação. Tal atividade pode ser vista como uma ponte que conecta duas pessoas separadas pela barreira linguística/cultural. Os tradutores possibilitam a comunicação entre membros de culturas distintas, transmitindo conhecimento e, finalmente, proporcionando comunicação. Dessa maneira, levando em consideração o ambiente observado (sala de aula de aprendizagem de língua inglesa), o contexto (ambiente de ensino/aprendizagem de língua inglesa em universidade), os aprendizes (estudantes vindos da comunidade em geral e da UFCG), o propósito da atividade de tradução (tornarem-se usuários de língua inglesa) e a função primordial de comunicar idéias e transmitir conhecimentos, apresentaremos a seguir as categorias de tradução de Jakobson.

\section{CATEGORIAS DE TRADUÇÃO DE JAKOBSON}

Jakobson (In VENUTI, 2000), foi um teórico que se destacou ao relacionar a tradução aos aspectos linguísticos de definição de signo. Para ele, o significado de qualquer palavra, frase ou imagem é definitivamente um fato linguístico-semiótico. Assim, Jakobson propôs três tipos de categorias de tradução que englobam a diversidade de significados dos signos utilizados para a comunicação.

A primeira delas é a Categoria Intralingual, ou reformulação, que é definida pelo autor como uma interpretação de signos verbais por outros signos em uma mesma língua. Este conceito está ligado às ideias de sinônimos, definições, equivalências e circunlocuções. Durante uma aula em Língua Estrangeira, por exemplo, um aluno que não entendeu o que significa a palavra notebook ${ }^{3}$ e perguntou ao professor, ouvindo a definição do termo, em inglês: 'it's a set of sheets joined together by a spiral or binded together like a book', ou simplesmente 'it's what you use to take notes" ${ }^{5}$ ou até usa um termo equivalente, como ' $b o o k^{, 6}$. Em todos esses casos, o professor se utilizou de signos verbais para explicar outro signo verbal da mesma língua.

A segunda categoria definida pelo teórico é a mais relacionada à ideia que se tem do que seja tradução. A Categoria Interlingual, ou tradução propriamente dita, é definida por Jakobson como sendo uma interpretação de signos verbais de uma língua por signos verbais de outra língua. Ou seja, a tradução aqui envolve "duas mensagens

\footnotetext{
3 "Caderno".

4 "É um conjunto de folhas unidas por um espiral ou presas como em um livro".

" "É o que você usa para fazer anotações".

6 "Livro".
} 
equivalentes, em dois códigos distintos" (Jakobson, In: VENUTI, 2000, p. 114). A leitura de um dicionário bilíngue, por exemplo, que traz um termo em inglês com seu equivalente em português e vice e versa, ou um aluno que pergunta "o que é 'notebook'?", e o professor que responde que "significa 'caderno"”, e tantas outras situações que ocorrem durante o uso de uma língua estrangeira, são exemplos dessa transposição de signos de uma língua para outra.

Por fim, mas não menos importante, está a Categoria Intersemiótica, ou transmutação, que é, na verdade, o ponto crucial desta pesquisa. Esta é definida pelo autor como a interpretação de signos verbais por sistemas de signos não-verbais e vice e versa. Isto é, a interpretação de uma imagem, figura, pintura, som, entre outros, em forma de um texto escrito ou discurso oral, são características desse tipo de tradução. No que diz respeito à transposição intersemiótica, Oustinoff (2011) afirma que este é um campo tão próximo e corriqueiro, que é difícil de perceber quando se realiza esse tipo de tradução. $\mathrm{O}$ autor também diz que estas transformações constituem um campo de estudo tão vasto e decorrem de transposições nas quais a parte de "imitação" é tão grande que não se consegue relacionar este campo à "tradução no sentido em que geralmente se entende esse termo" (OUSTINOFF, 2011, p.115). Com o avanço dos Estudos de Tradução, a ideia de que a tradução era apenas a transposição de signos verbais de uma língua para outra se ampliou e abrangeu a transposição dos mais variados signos linguísticos. Considerando-se que a palavra escrita é um significante visual e que dispomos de tantos outros significantes, a tradução passou a ser percebida em um sentido mais amplo pelo fato de que está presente em diversos contextos do cotidiano. Com relação à forma de transposição, Jakobson (In: VENUTI, 2000) ressalta que,

Só a transposição criativa é possível: Seja a transposição Intralingual - de uma forma poética para outra, ou Interlingual - de uma língua para outra, ou finalmente Intersemiótica - de um sistema de signos para outro, ex., de uma arte verbal para a música, dança, cinema ou pintura $^{7}$. (JAKOBSON, In: VENUTI, 2000, p.118, tradução minha).

\footnotetext{
7 Only creative transposition is possible: either intralingual transposition-from one poetic shape into another, or interlingual transposition-from one language into another, or finally intersemiotic transposition - from one system of signs into another, e.g., from verbal art into music, dance, cinema, or painting. (JAKOBSON, In: VENUTI, 2000, p.118).
} 
Assim, percebe-se que a utilização da categoria intersemiótica é uma ferramenta criativa que auxilia no aprendizado da língua estrangeira, como veremos no próximo ponto.

\section{TRADUÇÃO E ENSINO DE LÍNGUAS ESTRANGEIRAS}

Lucindo (1997) afirma que a utilização da tradução no ensino de línguas estrangeiras passou por várias mudanças ao longo do tempo. Primeiramente, surgiu o Método Gramática-Tradução (GT), que utilizava a tradução com o objetivo de capacitar alunos à leitura de textos literários e religiosos em Latim. No séc. XIX o Método GT foi trocado pelo Método Direto, que condenava o uso da tradução e da LM, dando ênfase, primeiramente, ao desenvolvimento oral. Foi com o surgimento da Abordagem Comunicativa $(\mathrm{AC})$ que a tradução e a língua materna começaram a voltar à cena. De acordo com Leffa (1988), a AC enfatiza a semântica da língua, em que a escolha linguística dependerá do contexto, do relacionamento entre os participantes e até das características intelectuais e afetivas do falante. Essa abordagem se preocupa com a linguagem de acordo com a situação em que há a realização da fala, semelhante a questões tradutórias descritas na Abordagem Funcionalista.

Coracini (2005) afirma que, durante certo tempo, a tradução foi banida das salas de aula de línguas estrangeiras (LE), por ser considerada como uma 'má influência' na aquisição de uma nova língua. Acreditava-se que o aluno devia deixar o conhecimento de língua materna (LM) de lado para que pudesse "realmente pensar como um falante" da LE. Porém, segundo a autora, estudos apontam para o uso de tradução como ferramenta eficaz em sala de aula. Para Coracini (2005), o sujeito-aluno já chega à sala de aula com uma carga de conhecimento e informação que influenciará no trabalho a ser realizado e na aquisição de novos conhecimentos. Segundo a autora, o conhecimento de mundo é inerente ao sujeito e tem influência sobre ele. Isso torna impossível o ensino de uma língua estrangeira sem haver relação com a língua materna.

A hipótese formulada por Coracini (2005) é que ambas (LE e LM) se interpenetram na constituição da subjetividade, ou seja, ambas se conectam durante o percurso de aprendizagem, de maneira natural e eficaz, uma influenciando na construção da outra. Neste caso, trabalha-se com estudantes universitários e da comunidade em geral que participam destas aulas com a intenção de desenvolverem as habilidades de escuta, fala, leitura e escrita em LE. São indivíduos que já vêm para a 
sala de aula com seu conhecimento de mundo e informações específicas de suas áreas, e esses conhecimentos influenciam diretamente nas atividades, que envolvem tradução, realizadas em sala de aula, já que esses estudantes buscam uma relação entre a LE e seus conhecimentos de LM, influenciando no desenvolvimento da LE.

A seguir, são apresentadas as análises das atividades coletadas no livro didático selecionado.

\section{ATIVIDADES COLETADAS NO LIVRO DIDÁTICO}

A partir das teorias de tradução, foi iniciada a coleta das atividades no primeiro volume da série 'English File', que é trabalhado nas primeiras turmas do Curso de Extensão de Inglês da UAL. Neste volume foram encontradas várias atividades que podem ser trabalhadas com o auxílio da tradução, tendo por base as Categorias de Tradução de Jakobson e a análise de como tais atividades podem ser trabalhadas em sala de aula pelo professor para que sejam, assim, classificadas nas diferentes categorias.

Para a análise, seguiu-se a fundamentação teórica já citada, que auxiliou na coleta e classificação das atividades, no sentido de que cada atividade dos livros didáticos tem objetivos previamente traçados e muitas delas são trabalhadas com o auxílio da tradução. O foco será dirigido aqui principalmente para as Categorias de Tradução propostas por Jakobson (1958/2000), que, como já mencionado anteriormente, se dividem em i) Interlingual, ii) Intralingual e iii) Intersemiótica. Foram coletadas e analisadas 45 atividades que envolviam tradução de alguma forma: na elaboração da atividade - atividades vindas da editora já com a função de utilizar tradução preestabelecida e na execução da atividade - atividade sem uso de tradução a primeira vista, mas supostamente trabalhada com o auxílio da tradução em sala de aula. Segue tabela demonstrativa:

Tabela 1: Atividades coletas no English File Elementary.

\begin{tabular}{|c|c|}
\hline Categorias de Tradução no English File & Quantidade de atividades \\
\hline Total de Atividades Coletadas & 45 \\
\hline Tradução Interlingual & 09 \\
\hline Tradução Intralingual & 21 \\
\hline Tradução Intersemiótica & 37 \\
\hline
\end{tabular}

Fonte: CLANDFIELD, Lindsay. LATHAN-KOENIG, Christina. OXDEN, Clive. TARGET, Francesca. SELIGSON, Paul. New English File - Elementary - Student's Book. Oxford: Oxford University Press. 2007. $1^{\mathrm{a}}$ Ed. 
A partir da análise feita, percebeu-se que algumas das atividades envolvendo tradução que foram coletadas não só se encaixavam nas categorias de Jakobson (ibid.), mas também envolviam duas (ou as três) categorias estabelecidas pelo teórico, envolvendo ainda muitas das características das outras teorias estudadas durante esta pesquisa.

A atividade 2 (Figura 1, abaixo), da página 06 do livro 'Elementary' da coleção 'English File', trabalha as habilidades de escuta e fala, que demandam escuta atenta de uma faixa de áudio que contém quatro conversações diferentes e, após ouvi-las, os alunos devem relacioná-las a quatro imagens que expressam o que as conversações dizem, de maneira não-verbal. Essa transposição, que é feita de elementos linguísticos verbais para não-verbais (e vice e versa), caracteriza o trabalho com a Tradução Intersemiótica, pois os alunos deverão fazer uma leitura das imagens para interpretar as ações, expressões faciais, pano de fundo das imagens e os próprios personagens descritos na imagem, para que possam relacioná-los às conversações escutadas. Esse tipo de atividade demanda um conhecimento prévio de mundo por parte dos alunos para que eles possam decodificar as imagens de uma maneira geral. Para isso, Coracini (2005) enfoca sua teoria na ideia de que esse conhecimento externo irá influenciar na boa execução do que foi proposto pela atividade e que de acordo com a habilidade de leitura (o termo 'leitura' aqui, não está restrito somente à leitura verbal) do aluno, o desenvolvimento da tarefa será afetado. 


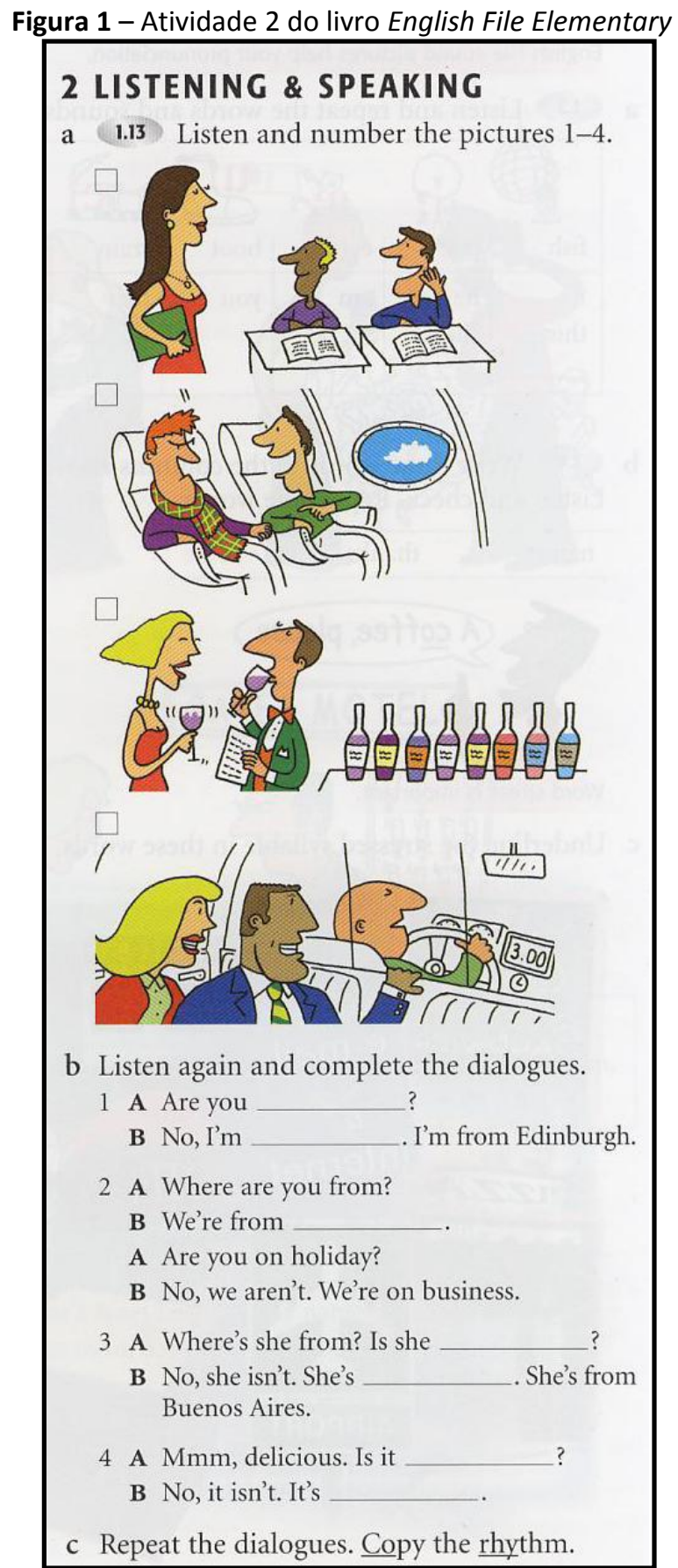

Fonte: CLANDFIELD, Lindsay. LATHAN-KOENIG, Christina. OXDEN, Clive. TARGET, Francesca. SELIGSON, Paul. New English File - Elementary - Student's Book. Oxford: Oxford University Press. 2007. $1^{\text {a } E d . ~}$

Outra atividade trabalhada com o auxílio da categoria de Tradução Intersemiótica de Jakobson foi a Atividade 1 (Figura 2, abaixo), da página 12 do livro. A atividade introduz um vocabulário relacionado a tipos de bebidas (ou 'drinks'), de maneira que os alunos relacionem uma lista de nomes de bebidas às suas imagens respectivas. Esse tipo de atividade também demanda o conhecimento prévio do aluno acerca desses tipos de bebidas que, provavelmente, o aluno já conhece em sua LM. A 
ação de ver uma imagem e relacioná-la a uma palavra caracteriza a Tradução Intersemiótica, por haver uma transposição de sentidos de um signo não-verbal para outro signo verbal. Ainda nessa atividade, as categorias de tradução Interlingual e/ou Intralingual serão trabalhadas. Pois, para a explicação do conteúdo ('drinks'), o professor irá, provavelmente, descrever a atividade e distribuir aos alunos a tarefa de relacionar as imagens aos seus respectivos nomes. O uso da tradução Interlingual ou Intralingual vai depender da metodologia do professor e da sensibilidade do mesmo ao identificar se o nível da turma é adequado à tradução Intralingual que, nesse caso, seria a explicação do conteúdo do livro, que é em inglês, na própria língua inglesa. Há uma grande chance de o professor usar a categoria de tradução Interlingual, tendo em vista que os alunos estão no início do aprendizado de outro idioma e que possivelmente terão dificuldades em entender as diretrizes dadas pelo professor em outro idioma.

Figura 2 - Atividade 1 do livro English File Elementary

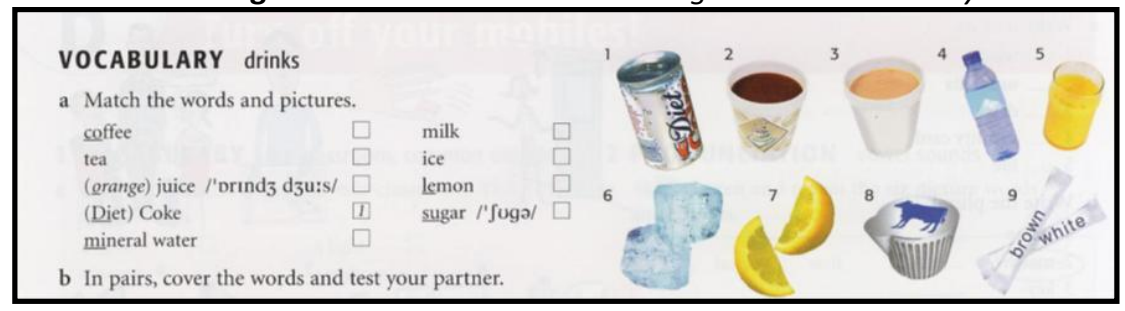

Fonte: CLANDFIELD, Lindsay. LATHAN-KOENIG, Christina. OXDEN, Clive. TARGET, Francesca. SELIGSON, Paul. New English File - Elementary - Student's Book. Oxford: Oxford University Press. 2007. $1^{\text {a }}$ Ed.

Por fim, foi observado que uma característica foi repetida ao longo das atividades coletadas. Os enunciados dessas atividades em geral fazem uso da categoria de tradução Intersemiótica, pois trazem signos não verbais que facilitam a compressão do que é demandado ao aluno. Na página 09 do livro, a atividade 01 (Figura 3, abaixo), por exemplo, demanda que os estudantes observem a palavra destacada e diferenciem se ela pertence à classe dos adjetivos ou à de pronomes. Para facilitar a compreensão do enunciado por parte dos alunos, a palavra 'highlighted', que significa em inglês significa 'destacada', aparece realmente destacada: 'highlighted'. Dessa forma, o aluno irá compreender o que o enunciado demanda, ainda que não haja ainda essa palavra em seu vocabulário. 
Figura 3 - Atividade 01 do livro English File Elementary

\section{GRAMMAR possessive adjectives}

a Look at the highlighted words. Which is an adjective? Which is a pronoun?

1 Where are you from? 2 What's your name?

Fonte: CLANDFIELD, Lindsay. LATHAN-KOENIG, Christina. OXDEN, Clive. TARGET, Francesca. SELIGSON, Paul. New English File - Elementary - Student's Book. Oxford: Oxford University Press. 2007. $1^{\text {a }}$ Ed.

Outro exemplo do uso da categoria Intersemiótica em enunciados pode ser encontrado na página 11 do volume, especificamente na atividade 03 (Figura 4, abaixo), em que um quadro explicativo denominado 'Giving Instructions' (Dando Instruções). Nesta atividade, o livro demonstra como se deve usar o termo 'please' (por favor) em diferentes tipos de frases: Afirmativas, Negativas e Interrogativas. Para facilitar o entendimento dos alunos, o conteúdo do livro é explicitado com o auxílio da categoria de tradução Intersemiótica que, nesse caso, faz a diferenciação dos tipos de frases utilizando elementos não verbais: o símbolo ‘+' para as frases afirmativas, o ‘-’ para as negativas e o símbolo '?' para as sentenças interrogativas. A utilização destes símbolos faz com que os alunos assimilem a informação nova, neste caso o uso do termo em inglês 'please', a partir de imagens simbólicas que já são de seu conhecimento prévio (o ‘+', o ‘-’, e o '?'), para que esse texto não verbal seja representativo de alguma forma no entendimento do texto verbal em inglês. 


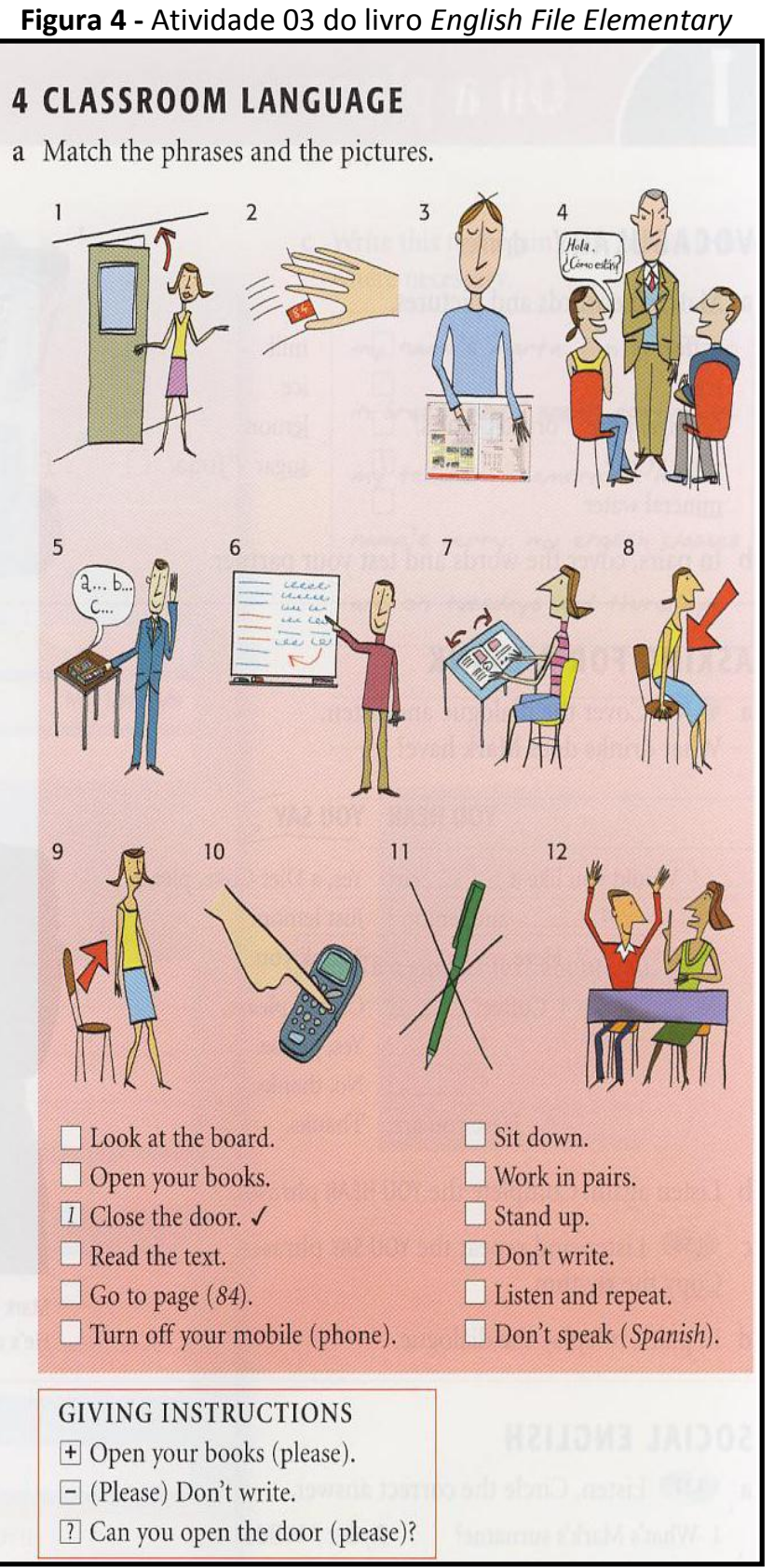

Fonte: CLANDFIELD, Lindsay. LATHAN-KOENIG, Christina. OXDEN, Clive. TARGET, Francesca. SELIGSON, Paul. New English File - Elementary - Student's Book. Oxford: Oxford University Press. 2007. $1^{\text {a }}$ Ed.

\section{CONCLUSÃO}

Em uma época de globalização e acesso a outras línguas e culturas, a visão sobre tradução tem se diversificado para atender as necessidades, seja de teóricos ou de tradutores. Oustinoff (2011) afirma que antes de se tornar um campo de estudo de cientistas, a tradução está presente em nosso cotidiano, pois ela constitui uma operação fundamental da linguagem. $\mathrm{O}$ autor ainda reforça a necessidade de se compreender que 
a tradução envolve o campo oral e escrito, verbal e não verbal, muito embora haja, na sociedade ocidental, a tendência de o escrito prevalecer sobre o oral.

A partir da teoria de tradução e análise de atividades que utilizam a tradução, como as que foram apresentadas acima, chega-se a conclusão que a distinção que Lucindo (1997) faz para dois tipos de tradução utilizados em sala de aula está presente na sala de aula de aprendizagem de línguas estrangeiras. Lucindo (ibid.), citando Hurtado Albir (1998), diz que a tradução interiorizada é inerente ao aluno, principalmente na fase inicial de seu aprendizado de LE. Esse fato é explicado pela LM ser o ponto de referência dos alunos, uma vez que chegam à sala de aula com seu conhecimento de mundo construído em LM, como afirma Coracini (2005). Tudo o que o aluno constrói ou desconstrói em LE dá-se a partir dos conhecimentos da LM. A tradução interiorizada tende a ser menos necessária à medida que o aluno vai desenvolvendo seu conhecimento e fluência na LE. Com isso, nos níveis iniciais, o uso de tradução é mais frequente, ocorrendo em todo (ou quase todo) tempo, diminuindo à medida que o aluno se torna linguisticamente mais competente em LE.

A tradução pedagógica, por sua vez, é utilizada em sala de aula como instrumento didático. De acordo com Lucindo (1997), o objetivo da tradução pedagógica é verificar ou reforçar a aprendizagem do aluno através da manipulação de textos (orais ou escritos), análise contrastiva e reflexão consciente. A tradução pedagógica difere da tradução interiorizada por ser controlada pelo professor, que irá limitar até que ponto a tradução será utilizada durante as aulas. É esse trabalho que se busca desenvolver em sala de aula na atualidade, mostrando ao aluno que nem sempre a tradução literal é a melhor opção, sendo necessário um trabalho detalhado com as partes do texto, levando em consideração o contexto, o propósito da atividade e o leitor/falante.

Coracini (2005) também afirma que muitos professores entendem que a tradução é positiva, mas não têm ideia de como utilizá-la. Cabe ao professor, portanto, buscar maneiras de incentivar o uso correto da tradução em sala de aula e procurar melhorar a sua formação e capacitação em LE com relação ao uso da ferramenta de tradução, não de forma literal, traduzindo palavra por palavra, mas utilizando a tradução dentro de um contexto, como foi visto da Abordagem Funcionalista. Por fim, o estudante deve ter a consciência de que a tradução só é útil em contexto de aprendizagem de LE dentro de um contexto e com propósito específicos, limitando seu uso a casos extremamente necessários. 


\section{AGRADECIMENTO}

Ao CNPq pelo financiamento do projeto e pela concessão da bolsa PIBIC. E à minha professora e orientadora Sinara de Oliveira Branco, por sua ajuda constante e interesse em meu crescimento acadêmico.

\section{REFERÊNCIAS BIBLIOGRÁFICAS}

CLANDFIELD, Lindsay. LATHAN-KOENIG, Christina. OXDEN, Clive. TARGET, Francesca. SELIGSON, Paul. New English File - Elementary - Student's Book. Oxford: Oxford University Press. 2007. $1^{a}$ Ed.

CORACINI, Maria José R. F. O sujeito tradutor entre a "sua" língua e a língua do outro. Em: Cadernos de Tradução. Florianópolis: Pós-Graduação em estudos da Tradução. 2005, pp. 09-24.

JAKOBSON, Roman. "On Linguistic Aspects of Translation". In: Venuti, Lawrence (ed.). The Translation Studies Reader. London: Routledge, 2000. p. 113-118.

HURTADO ALBIR, A. Hacia un enfoque comunicativo de la traducción. Em: II Jornadas Internacionales de Didáctica de Español Lengua Extranjera, Ministerio de Cultura, Madrid. 1998, pp. 53-79.

La traducción en la enseñanza comunicativa. Em: Cable: revista de didáctica del español como lengua extranjera. Madrid. 1998a, pp. 42-45.

LEFFA, V. 'Metodologia do ensino de línguas'. In: BOHN H. I; VANDRESEN, P. Tópicos em lingüística aplicada: o ensino de línguas estrangeiras. Florianópolis: Ed. da UFSC. 1998, pp. 211-236.

LUCINDO, E. S. 'Tradução e ensino de línguas estrangeiras.' Em: http://www.scientiatraductionis.ufsc.br/ensino.pdf, acessado em abril de 2009.

MALMKJAER, K. Translation and Language Teaching. Language Teaching and Translation. UK: St. Jerome. 1998. 
NORD, Christiane. Translating as a purposeful activity. Manchester: St. Jerome. 1997.

OUSTNOFF, Michaël. Tradução: História, teorias e métodos. Trad. Marcos Marcionilo. São Paulo: Parábola, 2011.

PEUGENAUTE, L. 'La traducción como herramienta didáctica.' In: Contextos, n²7-28, 1996, Madrid, $p$ 